\title{
PERFORMANCE EVALUATION MODEL AND ALGORITHM OF GREEN SUPPLY CHAIN MANAGEMENT BASED ON SUSTAINABLE COMPUTING
}

\begin{abstract}
How to facilitate collaborative development between the enterprise and the environment under the dual constraints of resources and the environment is the focus of today's green supply chain management system research. Through the performance evaluation of the green supply chain, we can understand the operation of the whole supply chain and its shortcomings, provide a basis for improving related processes, and have important practical significance for improving the competitiveness and protection of its products. First of all, by summarising and analysing the research status of sustainable supply chain management in different countries, the research idea and overall background of this paper are proposed. It discusses the theory of sustainable supply chain management and the performance evaluation system and calculation types of sustainable supply chain management. Finally, the relative weight of each index is determined based on the sustainability calculation method, and then the decentralisation degree of the index is constructed. During this period, the fuzzy comprehensive evaluation method is used to evaluate the performance of sustainable supply chain, conduct case analysis and summary, and evaluate the performance of green supply chain component in economic, social, environmental and other aspects. In this paper, representative companies are selected as examples to evaluate their green supply chain management performance, and the evaluation algorithm is studied based on sustainable calculation method. The results show that a reasonable and effective evaluation of the enterprise performance of green supply chain management and a sustainable algorithm study can effectively identify potential problems in the operation of the company and improve the overall operation of the company at this stage.
\end{abstract}

Keywords: green supply chain management, performance evaluation, evaluation model, algorithm research

\section{Introduction}

With the continued development of science and technology today, while bringing material wealth to humans, nature also suffers from the same environmental problems. In particular, in recent years, in order to seek growth, many enterprises have realised multiple connections of energy efficiency from product design, research and development, manufacturing, sales and after-sales processing in the fierce market competition, but at the same time, it has caused resource waste, environmental pollution and greenhouse effect resource depletion and other ecological and environmental problems [1]. In order to cope with the current environmental deterioration, relevant state institutions have also issued a series of laws and regulations, supervised by regulators and consumers, and achieved gradual results. Therefore, to truly limit environmental deterioration, we must adhere to the scientific outlook on Development. The scientific outlook on development needs to be people-oriented so as to achieve comprehensive, coordinated and sustainable development.

\footnotetext{
${ }^{1}$ Department of Finance, Nanchong Vocational and Technical College, Nanchong 637131, Sichuan, China, email: nzcjhc@163.com, ORCID: 0000-0003-0064-6461
} 
As an important unit of society, enterprises should strive to realise the best integration of three-dimensional integration of economy, environment and society, and realise the overall sustainable development. For example, Hong has incorporated the Green Concept into six aspects: product design, procurement, manufacturing, packaging, storage, transportation and recycling to establish a perfect green supply system rating system [2]. That same year, in a large electronics companies in the evaluation of green supply chain performance evaluation, has long been stressed while traditional factors enterprises focus on the first time, such as transportation, development, price, quality is the first point, but the long-term development of the environmental performance in green supply chain strategy is more important, to establish environmental performance affected by the supply and demand of enterprise business model, for green supply chain performance evaluation system carries on the preliminary elaboration and confirmed, to evaluate green supply chain system and advanced technology [3, 4].

At the same time, more and more Chinese researchers choose to explore green supply chain performance evaluation system from different dimensions. For example, economic performance, environmental performance, social performance, and business performance as starting points [5]. They believe that social responsibility is also an important perspective to evaluate the performance of green supply chain. Every firm recognises the need to understand the "environmental factors" in green supply chain decisions. At the business level, suppliers are responsible for five aspects: customer responsibility, environmental responsibility, protection of labour rights, social responsibility and creating a green social responsibility system for the supply chain. Currently, Chinese experts and researchers use a variety of methods to evaluate the performance of green supply chains. For example, Mondal et al. have constructed 48 green supply chain assessment indicators on five dimensions and believes that multi-assessment performance assessment should be implemented as a whole and multi-level assessment should be carried out without discrimination [6]. The overall level evaluation method is used to evaluate the overall performance, effectively avoiding artificial subjectivity and arbitrariness when verifying the accuracy of the method. In three aspects of cost effectiveness, environmental efficiency and business performance, the index system is constructed and the performance is analysed without difference. The results show that the implementation of green supply chain management by many companies is not sufficient, which reflects the imperfect operation of green supply chain. For example, Adelina and Kusumastuti believe that green supply chain aims to plan, organise and control logistics, capital flow, information flow and knowledge flow, and optimise the speed of related activities to improve efficiency and achieve environmental compatibility [7]. The reference sequence of this method does not affect the method itself, and its advantages include wide application, intuitive geometric definition, less computation, and high data fidelity. Green supply chain management increases the influence of social capital on enterprise performance through the double restriction of social credibility on enterprises, and obtains the corresponding theoretical basis by using structural equation model. Finally, it accelerates the improvement of environment and enterprise performance through social capital, and objectively evaluates the efficiency level of green supply chain.

This paper focuses on methods for evaluating sustainable supply chain performance. First of all, I will read magazines and classic books related to green supply chain, pay close attention to relevant information at home and abroad in real time, and provide theoretical guidance on the collection and classification of green supply chain theory, model making, 
model evaluation, and relevant research content evaluation. Second, a primary and secondary index evaluation matrix is created to determine preliminary weights for all index levels based on the principles of the sustainability algorithm, and a logical and formal application of the defined index weights. A test is run to confirm the possibility. The degree of decentralisation of each indicator is determined according to the highest, lowest and actual value of the indicator, and the indicator is sought. Finally, the degree of deviation is used to calculate the overall performance evaluation score of the sustainable supply chain according to the weight indicator and the degree of participation.

\section{Research on performance evaluation index system of green supply chain}

\section{The construction principle of green supply chain performance evaluation system}

The impact of product type, geographical area and supplier size on environmental performance (criteria) can be derived from the actual assessment of the company. Conclusion can be drawn from the accumulation of social capital, the impact of green supply chain management on supplier performance and the use of structural equation models. Green supply chains promote environmental, social and business improvements. Sustainable supply chain performance assessments need to be based on an overall sustainable supply chain strategy, and green supply chain performance metric systems have flexibility, functionality, dynamic and dynamic combinations, and economics. It must be established on the principles of systematic and scientific. Combination of green supply chain based on the theory of the equilibrium point method and social responsibility performance evaluation characteristics, from the economic value of green supply chain, customer service, business process and the ability to join the environmental and social responsibility, and try on the financial performance and non-financial performance, strike a balance between short-term and long-term value, reflecting the sustainable performance of a supply chain. In addition, the sustainable supply chain performance indicator system must be horizontal and vertical, so that the selected indicators can reflect the overall situation of the sustainable supply chain in a comprehensive, objective and realistic way. Output is evaluated according to indicators, while performance is measured according to indicators.

\section{Establishment of sustainable supply chain evaluation index system}

The sustainable supply chain performance evaluation is different from the general performance evaluation. The concept of sustainable development added in the traditional supply chain management theory is the name of green supply chain [8]. Compared with the general supply chain, the green supply chain has stronger environmental adaptability. This requires that all links in the green supply chain increase investment in science and technology and improve learning opportunities [9]. Therefore, the ability to learn and innovate is the key to the green supply chain and the competitive advantage that companies must gain. Evaluating the performance of large supply chain companies is a complex and systematic task. Creating a scientific, logical, and complete performance evaluation system is only the first step in systems engineering. If there is no scientific evaluation method, then the perfect index system is empty shell. The purpose of evaluating the performance of key supply chain operations is also empty. 
The first step in designing a sustainable green supply chain structure at all levels is to identify all the environmental factors that may affect the assessment. For example, by converting raw materials and other resources into finished products and other finished products that need to be consumed in the manufacturing process, enterprises will produce waste gases, solid wastes, noise interference and greenhouse gases, which will have a great impact on the environment [10]. Therefore, relevant enterprises in the supply chain must have a certain sense of social responsibility and environmental protection consciousness [11]. In the process of building a green supply chain, enterprises need to realise that growth is inclusive, which includes economic growth, social development and the establishment of an ecologically balanced environment.

\section{Selection of calculation methods for index weight}

Common weight calculation methods are divided into subjective weighting method and objective weighting method $[12,13]$. Among them, the subjective method is a kind of authorization method adopted according to the subjective concerns of decision makers. Its shortcoming is that it pays too much attention to the subjective factors while neglecting the objective factors such as research methods, scoring methods and stratified analysis methods. Therefore, at present, the comprehensive authorization method based on sustainable calculation is adopted to evaluate the weight of indicators, which combines the subjective authorization method and the objective authorization method to determine the weight method, taking into account the characteristics of preference, but at the same time can minimise the subjective arbitrariness, so as to achieve the unity of subjective and objective by strengthening the characteristics $[14,15]$. In this paper, we combine subjective and objective methods and use analytic hierarchy process and information entropy to calculate weights for each element of a company's green supply chain metrics system, effectively avoiding subjective colours. I will. It is a process of determining the weighting factor in the conventional evaluation method, and pays attention to the importance of the evaluation index itself.

\section{Analytic hierarchy process to find the weight}

The principle of Analytic Hierarchy Process (AHP) is to take a complex object problem as a system and decompose it into multiple levels through the analysis of the evaluation object [16]. The levels are based on collaboration, creating a smooth hierarchical model between all levels. According to the objective reality, the matrix table is determined by pairwise comparison, then the eigenvectors corresponding to the maximum eigenvalue of the matrix are used as corresponding coefficients (weights), and finally the weights of each layer are determined by a series of detection methods. This approach takes a unique approach to expertise to some extent. The core idea of AHP is to calculate and compare each factor to obtain the weight of influencing factors, and finally provide a decision basis for analysing and solving problems. It mainly includes the following three calculation steps:

(1) Establish the hierarchical structure model

The first step of Analytic Hierarchy Process is to establish a multilevel matrix module, which can be generally divided into the top layer (target layer), the middle layer (criteria layer) and the bottom layer (index layer).

(2) Construct judgment matrix

Matrix is the evaluation of the relationship between objective factors and other evaluation factors in the hierarchy. AHP uses analogies to provide quantitative analogies 
for the assessment of different situations [17]. In the actual calculation process, a pair of matrix tables must be constructed from the second layer of the hierarchical model, the numbers are 1-9, and the last layer is the same factor level belonging to each highest factor, up to the lowest level $[18,19]$.

The matrix table compares the relative importance of related factors in this hierarchy to the relative importance of higher level factors. Evaluate different situations using the ratio of numbers given at different levels. In a real computation, a pair of tables must be built from the second level of the hierarchical model, and their number ranges from 1 to 9 to the lowest level. When $i=j$ and $A_{i j}=1$, this means that the value is the same when comparing all levels of the same level [20-22].

As for the extracted index, it is specified as any set $U_{i}$, and the influencing factor is set as $A$, then the following judgment matrix is constructed:

$$
T=\begin{array}{cccc}
a_{11} & a_{12} & & a_{1 n} \\
a_{21} & a_{22} & \cdots & a_{2 n} \\
& \vdots & \ddots & \vdots \\
a_{n 1} & a_{n 2} & \cdots & a_{n n}
\end{array}
$$

in which $a_{11}=a_{22}=\ldots=a_{n n}=1$.

(3) Hierarchical single ordering - solve the eigenvector $W$

The hierarchical ranking of an aspect can be analysed according to the root matrix table, calculating the weights of the order of importance of factors related to that level and previous levels. The purpose is to use the summation method or square root method to calculate the maximum eigenvalue and corresponding eigenvector of each pair of patterns.

The specific calculation steps are as follows:

1) Calculate the product $M$ of the impact factors for each row of the judgment matrix $T_{i}$ :

$$
M=\prod_{j}^{n} x(i=1,2, \ldots, n)
$$

2) Calculate the square $\operatorname{root} \bar{W}$ :

$$
\bar{W}= \pm \sqrt{W}
$$

3) Calculate weight $T_{i}$ :

$$
T_{i}=W_{i} / \sum_{i=1}^{n} W_{i}
$$

\section{Determine the Index membership degree}

The concept of membership comes from the fuzzy evaluation function, which refers to the mapping function $F(X) \in[0,1]$ corresponding to a specific element $X$ in $Y$ region, then $F$ can be regarded as the fuzzy sum in $Y$, and $F(X)$ represents the participation degree of element $X$ relative to $F$. And, $F$ of $x$ can be viewed as a function of region $Y$. When $F(x)$ approaches 0 , this means that $x$ is a lower $x$ of the element $x$ of region $Y$, and vice versa.

The left membership function is:

$$
f(x)=\frac{x-a}{b-a} \quad x \in[a, b]
$$


The right membership function is:

$$
f_{1}(x)=\frac{c-x}{c-b} \quad x \in[b, c]
$$

As for performance evaluation rules, this paper defines the overall evaluation of sustainable supply chain indicators as five criteria. Taking resource recovery evaluation index as an example, we comprehensively use data query, expert consultation, social research and data analysis methods. Assuming that the minimum value of the resource recovery index is $4 \%$, the standard value is the maximum value obtained by the supply chain in the most reasonable case of $20 \%$, while the actual value of the index in the sustainable supply chain is $7.5 \%$. Therefore, we can get the participation rate of this indicator between 10,21 and $7.5 \%$, closer to $8 \%$. This indicates a high participation rate at the assessment level, which equates to a participation rate of $6 \%$ at the assessment level below $8 \%$. The final calculation shows that the left participation rate of resource recovery rate and reuse rate is: $30 \%$ and the correct participation rate is: $70 \%$.

\section{Consistency test}

Conformance testing is a decision making method based on fuzzy set, using mathematical analysis method of fuzzy variable layer to no difference factor number set comprehensive analysis, the method of some impact factors and the number of sets with the analysis of the natural advantages and can be from food alone to point is below the point of view of evaluation, finally, for sure the only reasonable to calculate the final result:

Calculate the maximum eigenvalue of the judgment matrix:

$$
\lambda_{\max }=\frac{1}{n} \sum_{i-1}^{n} \frac{(B W)_{i}}{W_{i}}
$$

Then, the random consistency index, $C I$ is shown:

$$
C I=\frac{\lambda_{\max }}{n-1}
$$

Therefore, consistency detection is shown in formula:

$$
C R=C I / R I
$$

where $C R$ represents the consistency ratio and $R I$ - the average random consistency index.

\section{Determine the relative weight of each layer based on sustainable calculation}

The information entropy calculation method is an objective weighting method in the analytic hierarchy process compared to the expert classification method, and subjectively emphasises weighting. Information entropy is a type of quantity used to reflect information deficits in information theory. "Entropy" is used to measure the uncertainty of the index. Entropy means that the higher the degree of information disturbance, the smaller the information provided by the index, the higher the balance of data, the smaller the role played by the index in the overall assessment, and the smaller its weight. The specific steps of information entropy weight calculation are as follows:

Normalise the digital matrix:

$$
y=\frac{x_{i j}-\min \cdot\left(x_{i j}\right)}{\max \cdot\left(x_{i j}\right)-\min \cdot\left(x_{i j}\right)}
$$


where $\max .\left(x_{i j}\right)$ and $\min .\left(x_{i j}\right)$ correspond to the maximum and minimum values in column $J$ of the $X$ data table, respectively. Since the entropy used to calculate weights is not used to estimate the actual entropy (the amount of information), it should reflect the role of the corresponding rating index in the standard rating system. Its calculated entropy value is:

$$
\begin{gathered}
H_{j}=-\frac{1}{\ln n} \sum_{i-1}^{n} a_{i j} \ln a_{i j} \\
a_{i j}=\frac{y_{i j}}{\sum_{i-1}^{n} y_{i j}}
\end{gathered}
$$

Calculate the weight of evaluation index:

$$
w_{j}=\frac{1-H_{j}}{n-\sum_{j-1}^{m} H_{j}}
$$

\section{Combined weight calculation}

Sustainable supply chain performance portfolio weight evaluation is based on the neural network removed from the human brain to create a neural network model with specific functions. This method uses adaptive methods to process brain-type information and can effectively adapt, learn on their own and quickly find the best solution. The downside is that before you apply this approach, you must ensure that you have a large sample to train and learn the network, and that weight and thresholds are determined accordingly. In practical studies, it is much more difficult to obtain a large number of standard data samples due to trade secrets and other systematic reasons. The combination calculation is performed by using the linear weighting method:

$$
\bar{W}_{i}=K_{i} W_{i 1}+K_{2} W_{i 2}
$$

\section{Comprehensive evaluation of green supply chain model}

Finally, the known information is classified and processed to determine the state of the object to be evaluated according to the predetermined target at a given stage, and the judgment of the latter process can use the results of the previous process as the input basis. The efficiency of complex system evaluation is significantly improved by multistage processing and circular method. This method is suitable for multi-factor comprehensive evaluation structure system, and the established comprehensive evaluation model of green supply chain is as follows:

$$
Z=\sum_{i=1}^{n} W_{i} F_{i}
$$

where $Z$ represents the overall parameter of the green supply chain system; $W_{i}$ - the decentralised participation value of each sub-indicator; $F_{i}$ represents the authenticity assignment of each indicator. 


\section{Experimental study on performance evaluation index system of green supply chain}

\section{Sample of experimental data}

Company B currently has three major subsidiaries: Projector Company, Intelligent Systems Company and medical services Company. Among them, the revenue of projection equipment companies accounts for almost $90 \%$ of the total revenue. Company $\mathrm{B}$ has established its own brand, which uses the most advanced LCD imaging technology in the industry, and is committed to displaying the entire intelligent manufacturing system and platform industry structure of the machine. Since its establishment in 1993, B Company has been following the customer-centered mechanism of "creating value and win-win cooperation", responding quickly to customers' needs and market trends, and providing new and old customers with the best quality products. Company B provides LCD screens and projection screens to many downstream customers, including world famous electronic information companies. In addition, Company B attaches great importance to research and development and independent innovation. The proportion of investment in research and development technology remained between 7 and $9 \%$. Investment in scientific research and development has increased year by year, maintaining the industry's leading level.

\section{Collection of experimental data samples}

The data of this paper comes from the following aspects:

(1) The basic data of Company B is obtained by communicating with the leaders of Company B's finance department, material management department, production department, customer service department and other relevant departments.

(2) For the unique and unique data of the industry, mainly refer to relevant national industry regulations, industry data and expert Suggestions.

(3) Due to the high degree of uncertainty and subjectivity of the original data, part of the data is obtained by making relevant corrections based on the data of the same industry. Make corrections according to the relevant performance appraisal regulations, and use numerical values to represent the results of the appraisal level.

\section{Establish a green supply chain evaluation system model for experimental subjects}

Following relevant business documents and standards, this paper provides a detailed introduction to the relationship between green supply chain systems and economic, social and environmental systems and provides a rationale for the design of green supply chain system frameworks and selection indicators. The comprehensive evaluation index design and index selection are carried out, the pre-evaluation system and the corresponding index framework are defined, the pre-evaluation index system is tested and improved, and the final evaluation system model is determined.

\section{Establishment of hierarchy and calculation of weights}

In this paper, the hierarchical fuzzy analysis method of green supply chain evaluation based on sustainable calculation is mainly used to determine the comparative weight of each index. Firstly, the data is used to construct the green supply chain architecture and determine the weight ratio of each index. Then, the membership degree of each item is obtained by using the sustainable calculation method in this paper, and the index weight of 
each item is calculated by combining the membership matrix. Finally, the component value is converted to complete the comprehensive evaluation of enterprise green supply chain system.

\section{Experimental analysis of green supply chain performance evaluation index system}

\section{Index weights of sustainable supply chain at all levels}

The above construction of company B's green supply chain rating system is a typical evaluation model of multi-level and multi-function scoring. In a rating index system, it includes not only quantitative indicators, such as capacity utilisation and energy consumption, but also quality indicators, such as workers' working conditions and deliverables. Therefore, after the comparative analysis of the above five methods, this paper mainly uses AHP and fuzzy evaluation method to evaluate the green supply chain implementation ability of B Company. It can analyse the stratification process by analysing the weight of each index. Company B's green rating can be achieved by a fuzzy evaluation method. After the specific weight ratio of each indicator is obtained, the comprehensive evaluation of the weight of four major indicators, namely production process, financial value, society and environment is obtained respectively, so as to obtain the membership degree of the whole sustainable supply chain.

Weight of second-level indicators

\begin{tabular}{|c|c|c|c|c|c|c|}
\hline Project & v1 & v2 & v3 & v4 & $\boldsymbol{w}_{\boldsymbol{i}}$ & $\boldsymbol{W}_{\boldsymbol{i}}$ \\
\hline U1 & 0.52 & 0.40 & 0.048 & 0.33 & 120 & 0.5836 \\
\hline U2 & 0.10 & 0.08 & 0.046 & 0.032 & 2.667 & 0.2254 \\
\hline U3 & 0.30 & 0.06 & 0.044 & 0.029 & 0.3 & 0.1333 \\
\hline U4 & 0.10 & 0.03 & 0.015 & 0.01 & 0.01 & 0.0576 \\
\hline
\end{tabular}

Taking production and operation indicators as an example, the weight of second-level indicators can be obtained from Table 1. Similarly, the membership of financial value, social and environmental indicators can be reflected in the table, and then the membership of the four indicators can be weighted to obtain the comprehensive fuzzy evaluation set of the final sustainable supply chain.

\section{Weight analysis of sustainable supply chain}

In this paper, the sustainable computing hierarchical fuzzy method is mainly used to evaluate the comparative weight of each index. First of all, the comparative scores of each indicator are determined by expert scoring. Then, the specific calculation method used in this paper is used to obtain the weight of each indicator as shown in Figure 1.

As shown in Figure 1, the membership degree of financial indicators, social indicators and environmental indicators can also be obtained by the same method. Among them, taking production and operation indicators as an example, the weight values can be obtained from Table 1. The vector matrix of the degree of membership of the production operation index can be obtained by multiplying the weight vector of the quadratic index of the production operation index by the membership matrix of the matrix index. Similarly, the membership of financial value, social and environmental indicators can be obtained. 


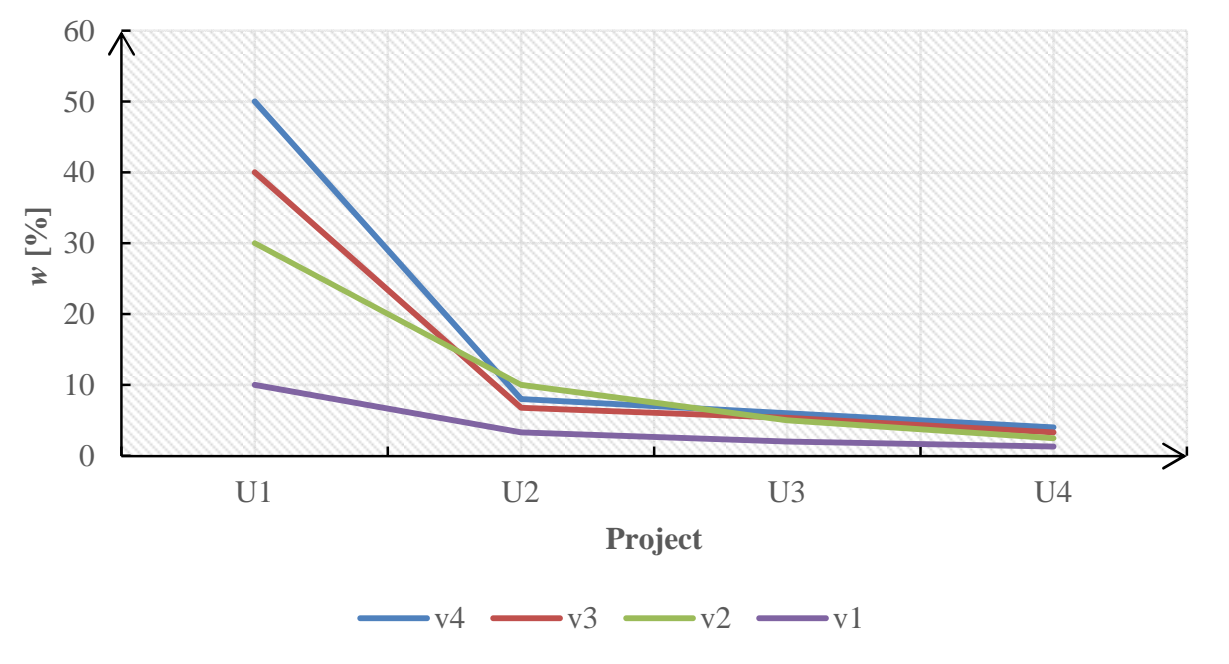

Fig. 1. Weight of second-level indicators

\section{Fuzzy comprehensive evaluation of sustainable supply chain}

Specific membership degree of each index, then calculate respectively the production process, financial value, society and environment of the four major indicators of membership degree comprehensive evaluation, so as to get the membership degree of sustainable supply chain, for each layer of index to evaluate the importance degree of two elements, the ratio of the elements of judgement matrix corresponding values, and using the analytic hierarchy process (AHP) to calculate the weight of each index. Specific results are shown in Figure 2.

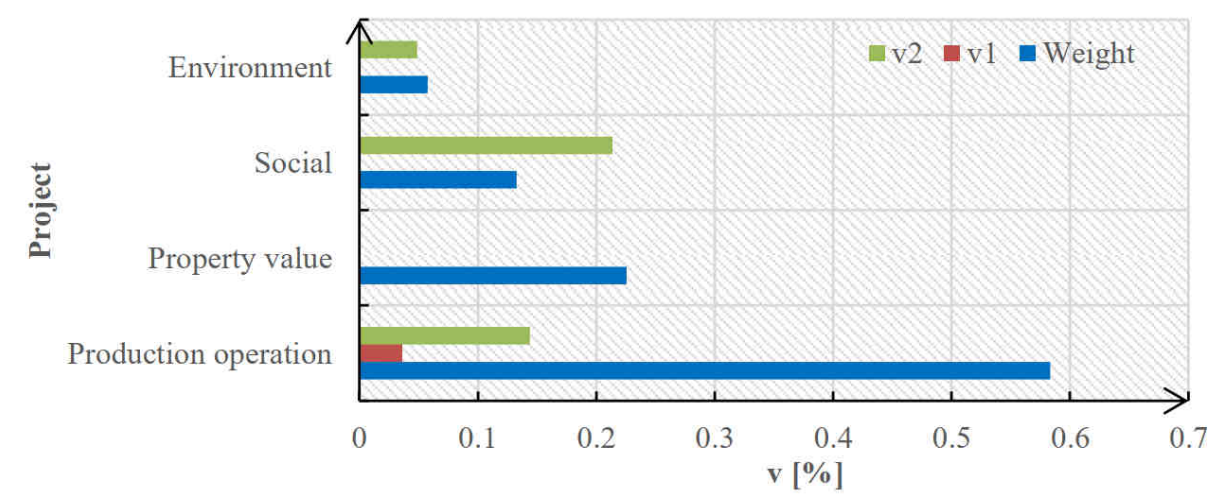

Fig. 2. Membership of overall evaluation of sustainable supply chain 
Among them, taking production and operation indexes as an example, the vector matrix of the second-level index weight of production and operation indexes and the index membership matrix can be obtained by multiplying the vector matrix of the index membership. Similarly, the membership degree of financial value, social and environmental indicators in Figure 2 can be obtained. When the degree of inconsistency is within the allowable range, the ranking result has satisfactory consistency, and then the weight coefficient distribution is also reasonable. Otherwise, it is necessary to adjust the value of the elements of the judgment matrix and redistribute the value of the weight coefficient. Then the membership degree of the four indexes is weighted to obtain the comprehensive fuzzy evaluation set of the final sustainable supply chain.

\section{Evaluation results and analysis of results}

Combined with the percentage system of various indicators in Figure 2, the overall evaluation scores of each sustainable supply chain in Figure 3 can be compared before and after the implementation of the overall performance. The hierarchy structure, evaluation set and score set of the evaluation object are constructed. The weights of each evaluation index are determined and counted through the analytic hierarchy process.

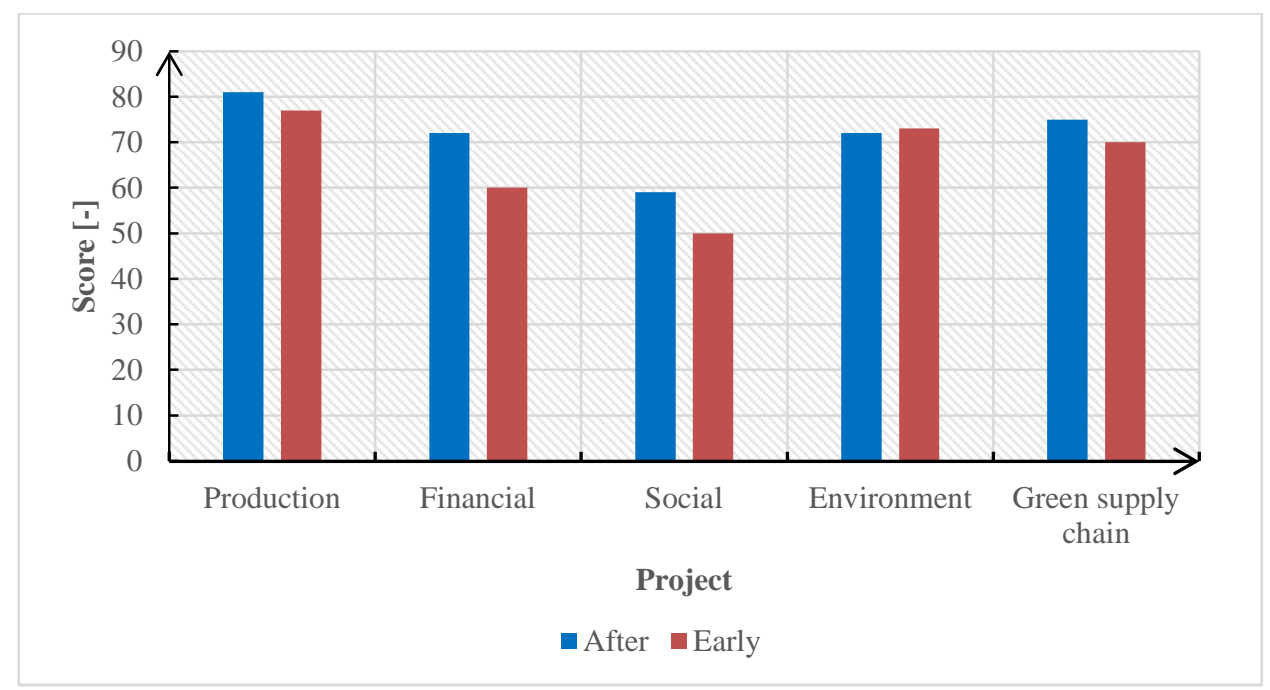

Fig. 3. Overall performance evaluation of sustainable supply chain

As shown in Figure 3, after the implementation of green supply chain system sustainable supply chain of the enterprise integrated performance evaluation score is 75.77 , the reference standard is between 70-85, 75.77 above has been using analytic hierarchy process (AHP) to determine the relative importance of each index, then calculate the weight coefficient of the performance evaluation, it can be seen that it has reached a good level, the enterprise's sustainable supply chain management in general level, but more early indicators improved significantly, the breakdown of the weighted distribution subsidiary as shown in Figure 4. 


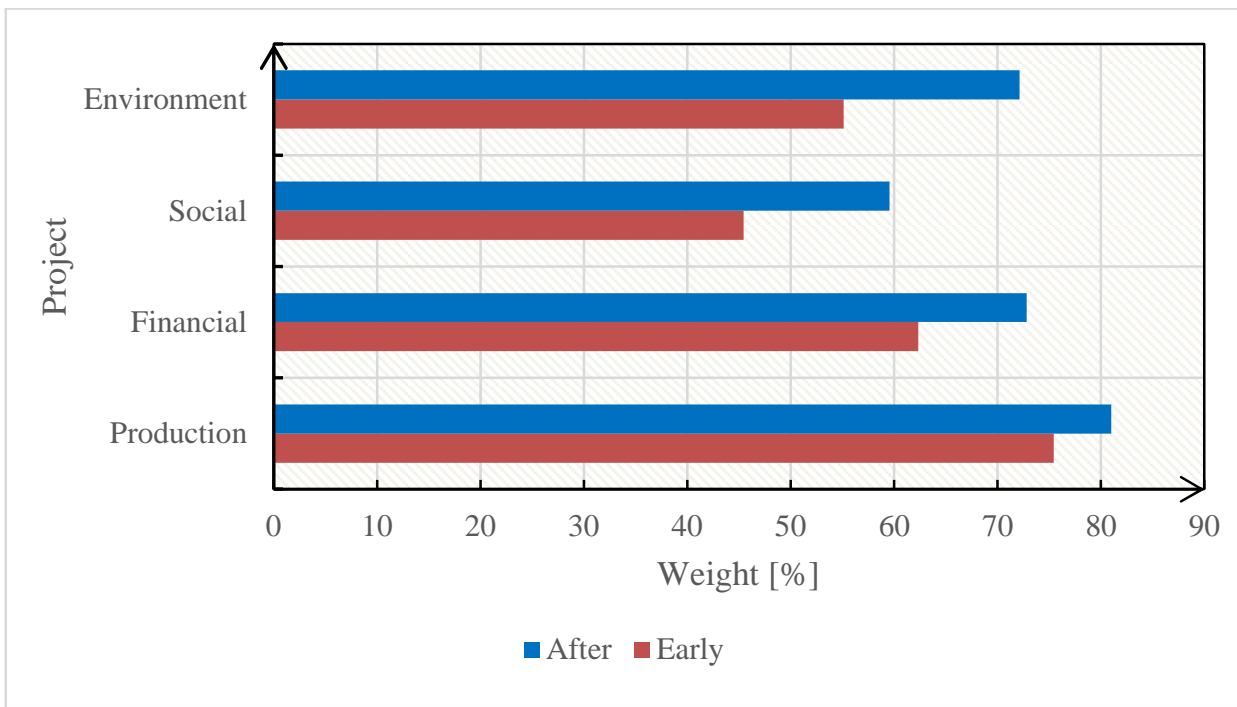

Fig. 4. Time weight of sustainable supply chain

After weighted score, we can know the value of the two-level index is: production and operation score: 81.014 , financial value score: 72.816 , social score: 59.566 , environment score: 72.14. Obviously, due to the high degree of enterprise informatization, flexible production and rapid market response, the production and operation score is relatively high. The link between production and manufacturing in the supply chain is primarily the responsibility of the upstream company and has little impact on the overall environment. However, the low score of social responsibility indicates that the social influence of enterprises is not big enough, the sense of social responsibility is not strong enough, and the social role is not obvious enough. In order to achieve the goal of sustainable supply chain management, on the one hand, we should strengthen the government's management and publicity. In addition, enterprises should also enhance their own social and environmental awareness, and effectively improve the shortcomings of the supply chain.

\section{Conclusion}

This paper mainly starts from the perspective of green supply chain and obtains relevant theories and research results by studying the literature on performance evaluation of green supply chain at home and abroad. In a specific study, the construction of its index system, the application of evaluation methods and the actual application of green supply chain performance evaluation at home and abroad are studied. This work is based on the existing research results, combined with their own actual situation, to understand the selected topics and implement the main courses. This treatise builds a multi-layered green supply chain evaluation model from three dimensions: social performance, economic performance, and social performance. The continuous performance evaluation system evaluates the fuzzy hierarchical model based on sustainability calculation, and then selects the example of Company B. Layered imaging analysis and fuzzy evaluation method are combined to achieve the overall performance evaluation of the selected company. Calculate 
the weight factor of each index level, score according to the importance of the index, create correlation matrix, use feature vector to calculate, obtain the overall evaluation result, and then calculate the actual application status of the company in environmental protection.

For this research project, the performance of the green supply chain constructed in this paper is expected to be further improved. In the analysis of some real company data, the combination of algorithm evaluation and mathematical statistics may filter out the real indicators, but it will still lead to some internal and external factors that have not been found out and removed, thus causing abnormal weight classification to affect the assessment results.

In this paper, there are a lot of determined components and uncertain factors in the evaluation model of sustainable supply chain index system. In addition, different industries have different concentrations of supply chain impact indicators. Therefore, it is necessary to strengthen the validation of evaluation models in order to increase the flexibility of evaluation systems of different disciplines. Sustainable supply chain requires the sustainable development of the whole society, and the company's business goal is to maximise its own interests. How to solve this contradiction and how to realise sustainable supply chain management will also be the focus of future academic research.

\section{References}

[1] Kitouni I, Benmerzoug D, Lezzar F. Smart agricultural enterprise system based on integration of internet of things and agent technology. J Organizational End User Computing. 2018;30(4):64-82. DOI: 10.4018/JOEUC.2018100105.

[2] Hong Y, Huang H, Dai S. An in vivo study of the best light emitting diode (LED) systems for cut chrysanthemums. Open Life Sciences. 2015;10(1):310-21. DOI: 10.1515/biol-2015-0031.

[3] Tsai SB, Chien MF, Xue Y, Li L, Jiang XD, Chen, Q, et al. Using the fuzzy DEMATEL to determine environmental performance: a case of printed circuit board industry in Taiwan. PLOS ONE. 2015;10(6):e0129153. DOI: 10.1371/journal.pone.0129153.

[4] Reddy MR, Srinivasa KG, Reddy BE. Smart vehicular system based on the internet of things. J Organizational End User Computing. 2018;30(3):45-62. DOI: 10.4018/JOEUC.2018070103.

[5] Sivarajah U, Weerakkody V, Waller P, Lee H, Irani Z, Choi Y, et al. The role of e-participation and open data in evidence-based policy decision making in local government. J Organizational Computing Electronic Commerce. 2016;26(1):64-79. DOI: 10.1080/10919392.2015.1125171.

[6] Mondal HK, Gade SH, Kishore R, Deb S. P 2 NoC: power-and performance-aware NoC Architectures for sustainable computing. Sust Computing: Informatics Systems. 2017;16(5):25-37. DOI: 10.1016/j.suscom.2017.08.005.

[7] Adelina W, Kusumastuti RD. Green supply chain management strategy selection using analytic network process: case study at pt xyz. IOP Conf Series: Materials Sci Eng. 2017;166(1):012-26. DOI: $10.1088 / 1757-899 X / 166 / 1 / 012026$.

[8] Kim H. Investigating the mediating role of social networking service usage on the big five personality traits and on the job satisfaction of Korean workers. J Organizational End User Computing. 2019;31(1):110-23. DOI: 10.4018/JOEUC.2019010106.

[9] Tsai SB, Wei YM, Chen KY. Evaluating green suppliers from green environmental perspective. Environ Planning B: Planning Design. 2016;43(5):941-59. DOI: 10.1177/0265813515600897.

[10] Bai C, Sarkis J. Evaluating complex decision and predictive environments: the case of green supply chain flexibility. Technol Economic Development Economy. 2018;24(4):1630-58. DOI: 10.3846/20294913.2018.1483977.

[11] $\mathrm{Hu} \mathrm{S,} \mathrm{Yu} \mathrm{B,} \mathrm{Yu} \mathrm{H.} \mathrm{IEEE} \mathrm{Transactions} \mathrm{on} \mathrm{Sustainable} \mathrm{Computing:} \mathrm{Guest} \mathrm{Editorial} \mathrm{on} \mathrm{Special} \mathrm{Issue} \mathrm{on}$ Sustainable Cyber-Physical Systems. IEEE Trans Sust Computing. 2018;3(2):58-9. DOI: 10.1109/TSUSC.2017.2770318.

[12] Tsai SB, Wang K. Using a novel method to evaluate the performance of human resources in green logistics enterprises. Ecol Chem Eng S. 2019;26(4):629-40. DOI: 10.1515/eces-2019-0045.

[13] Chen YX, Li L, Yu J, Tsai SB, Wang JT. An empirical study on environmental efficiency measurements and influencing factors. Ecol Chem Eng S. 2020;27(4):543-53. DOI: 10.2478/eces-2020-0033. 
[14] Mahalakshmi GS, Muthuselvi G, Sendhilkumar S, Vijayakumar P, Zhu Y, Chang V, et al. Sustainable computing based deep learning framework for writing research manuscripts. IEEE Trans Sust Computing. 2018;4(1):4-16. DOI: 10.1109/TSUSC.2018.2829196.

[15] Sołowski G, Konkol I, Cenian A. Perspectives of hydrogen production from corn wastes in Poland by means of dark fermentation. Ecol Chem Eng S. 2019;26(2):255-63. DOI: 10.1515/eces-2019-0031.

[16] Dauwe D, Jhaveri R, Pasricha S, Maciejewski AA, Siegel HJ. Optimizing checkpoint intervals for reduced energy use in exascale systems. 2017 Eighth International Green and Sustainable Computing Conference (IGSC), Orlando, FL, USA. 2017;1:1-8. DOI: 10.1109/IGCC.2017.8323598.

[17] Rauber T, Runger G, Stachowski M. Model-based optimization of the energy efficiency of multi-threaded applications. 2017 Eighth International Green and Sustainable Computing Conference (IGSC), Orlando, FL, USA. 2017;1:1-6. DOI: 10.1109/IGCC.2017.8323578.

[18] Ghosh SK. Impact of implementation of green supply chain management practice in production industry: a review. Int J Res Appl Sci Eng Technol. 2017;10:1622-9. DOI: 10.22214/ijraset.2017.8230.

[19] Zampese E, Moori RG, Caldeira A. Green marketing as a mediator between supply chain management and organizational performance. RAM. Revista de Administração Mackenzie 2016;17(3):183-211. DOI: 10.1590/1678-69712016/administracao.v17n3p183-211.

[20] Marszałek M, Kowalski Z, Makara A. The possibility of contamination of water-soil environment as a result of the use of pig slurry. Ecol Chem Eng S. 2019;26(2):313-30. DOI: 10.1515/eces-2019-0022.

[21] Prakash C, Barua MK. Integration of AHP-TOPSIS method for prioritizing the solutions of reverse logistics adoption to overcome its barriers under fuzzy environment. J Manufacturing Systems. 2015;37(3):599-615. DOI: 10.1016/j.jmsy.2015.03.001.

[22] Fabisiak L. Web service usability analysis based on user preferences. J Organizational End User Computing. 2018;30(4):1-13. DOI: 10.4018/JOEUC.2018100101. 